\title{
ALTERAÇÕES DE PESO EM NONAGENÁRIOS E CENTENÁRIOS DURANTE A PANDEMIA DE COVID-19
}

Liziane da Rosa Camargo*; Escola de Medicina da PUCRS, Porto Alegre, Brasil; lizicamargo.nutri@gmail.com

Cintia Cristina Sulzbach*; Escola de Medicina da PUCRS, Porto Alegre, Brasil; cintia.sulz@gmail.com Renata Breda Martins*; Escola de Medicina da PUCRS, Porto Alegre, Brasil; nutrirenatamartins@gmail.com Ângelo José Gonçalves Bós*; Escola de Medicina da PUCRS, Porto Alegre, Brasil; angelo.bos@pucrs.br

*Projeto de extensão Atenção Multiprofissional ao Longevo (AMPAL) da PUCRS, Porto Alegre, Brasil

\section{RESUMO}

Introdução: É importante monitorar o peso de nonagenários e centenários, principalmente em situações como a COVID-19, pois mudanças ponderais podem refletir no declínio da saúde. Objetivo: Observar alteração de peso em nonagenários e centenários durante a pandemia da COVID-19. Métodos: Estudo observacional e transversal realizado com nonagenários e centenários participantes do Projeto Atenção Multiprofissional ao Longevo. A coleta foi realizada por ligações telefônicas ou videoconferência entre março a agosto de 2020. Variáveis avaliadas: características sociodemográficas, Índice de Massa Corporal (IMC) classificado em baixo-peso $\left(<23 \mathrm{~kg} / \mathrm{m}^{2}\right)$, peso adequado $\left(23-28 \mathrm{~kg} / \mathrm{m}^{2}\right)$, excesso de peso $\left(>28-30 \mathrm{~kg} / \mathrm{m}^{2}\right)$ e obesidade $>30 \mathrm{~kg} / \mathrm{m}^{2}$. Os participantes foram também questionados sobre alterações de peso nas últimas 2 semanas, compra e preparo dos alimentos (participante, familiar ou não-familiar). Resultados: 59 participantes, $78 \%$ mulheres, $96 \pm 3,8$ anos, $81,4 \%$ moravam acompanhados. Peso médio: $58 \pm 9,5 \mathrm{~kg}, 53 \%$ peso adequado, $32 \%$ baixo-peso, $9 \%$ obesidade, $6 \%$ excesso de peso. $59 \%$ mantiveram o peso estável, $24 \%$ perderam peso, $17 \%$ ganharam peso. As compras foram realizadas em $83 \%$ pelo familiar, $15 \%$ não-familiar e $2 \%$ participantes. O preparo do alimento foi feito em $51 \%$ pelo, $36 \%$ por não-familiar e $14 \%$ participantes. Conclusão: A maioria dos entrevistados estavam com peso adequado e estável, recebendo suporte familiar para a compra e preparo da alimentação. Entretanto, um número importante estava com baixo-peso e perdeu peso corporal durante a pandemia. Como nonagenários e centenários é um grupo etário com maior fragilidade e vulnerabilidade é importante monitorar o peso os fatores que podem estar associado com alterações corporais dos mesmos.

Palavras-chaves: Idoso de 80 anos ou mais; Índice de massa corporal; Infecções por coronavirus.

Agradecimentos: O presente trabalho foi realizado com o apoio da Coordenação de Aperfeiçoamento de Pessoal Nível Superior - Brasil (CAPES) - Código de Financiamento 001. 